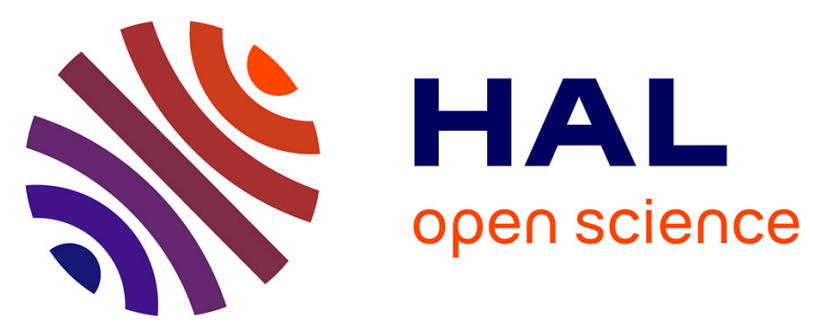

\title{
Design of cytocompatible bacteria-repellent bio-based Polyester films via an aqueous photoactivated process
}

Michael Condat, Christophe Hélary, Thibaud Coradin, Pierre Dubot, Julien

Babinot, Marco Faustini, Samir Abbad Andaloussi, Estelle Renard, Valérie Langlois, Davy-Louis Versace

\section{To cite this version:}

Michael Condat, Christophe Hélary, Thibaud Coradin, Pierre Dubot, Julien Babinot, et al.. Design of cytocompatible bacteria-repellent bio-based Polyester films via an aqueous photoactivated process. Journal of materials chemistry B, 2016, 4 (16), pp.2842-2850. 10.1039/C5TB02659H . hal-01307635

\section{HAL Id: hal-01307635 \\ https://hal.sorbonne-universite.fr/hal-01307635}

Submitted on 26 Apr 2016

HAL is a multi-disciplinary open access archive for the deposit and dissemination of scientific research documents, whether they are published or not. The documents may come from teaching and research institutions in France or abroad, or from public or private research centers.
L'archive ouverte pluridisciplinaire HAL, est destinée au dépôt et à la diffusion de documents scientifiques de niveau recherche, publiés ou non, émanant des établissements d'enseignement et de recherche français ou étrangers, des laboratoires publics ou privés. 


\title{
Design of cytocompatible bacteria-repellent bio-based Polyester films via an aqueous photoactivated process
}

Received 00th January 20xx, Accepted 00th January 20xx DOI: $10.1039 / \times 0 \times x 00000 x$

www.rsc.org/

\author{
Michael Condat ${ }^{a}$, Christophe Helary ${ }^{b}$, Thibaud Coradin ${ }^{b}$, Pierre Dubot $^{a}$, Julien Babinot ${ }^{a}$, Marco \\ Faustini ${ }^{\mathrm{b}}$, Samir Abbad Andaloussi ${ }^{\mathrm{c}}$, Estelle Renard ${ }^{\mathrm{a}}$, Valérie Langlois ${ }^{\mathrm{a}}$, Davy-Louis Versace ${ }^{\mathrm{a}^{*}}$.
}

\begin{abstract}
Nosocomial infections are often induced by the presence of pathogenic organisms on the surface of medical devices or hospital equipment. Chemical or topographical modifications of the surface are recognized as efficient strategies to prevent bacteria adhesion but they may have negative impact on the material interaction with living tissues. Here we have developped a photoactivated method for the modification of a biocompatible polymer, Poly(3-hydroxybutyrate-co-3hydroxyvalerate) (PHBHV) in aqueous conditions. A photoinduced free-radical technique employing a grafting-from process in water media has been successfully performed to covalently anchored fluorine or PEG groups onto PHBHV surfaces. PEGylated hydrophilic surfaces showed higher bacteria-repellency performances than fluorinated hydrophobic films, achieving a > $98 \%$ anti-adhesion efficiency against Escherichia coli and Staphylococcus aureus. In addition, these surfaces allowed for the adhesion and proliferation of human dermal fibroblasts without evidence of cytotoxicity.
\end{abstract}

\section{Introduction}

Infections by pathogenic microorganisms are of great concern, particularly in medical devices and in hospital surfaces/furniture. Statistics reveal that the average incidence of secondary infections affects $8 \%$ of all hospitalized patients (10\% in Great Britain, $6.7 \%$ in Italy and $8.7 \%$ in Finland). In 2002, the healthcare-associated infections (HAI) and deaths in United States hospitals were evaluated at least at 2 million among the 37.7 million admissions ${ }^{1}$. The estimated deaths associated with these HAls were 100,000 resulting from pneumonia, bloodstream infections, urinary tract infections, surgical site infections, and infections of other sites. Most of these medical errors are preventable. Hospital-acquired infections ${ }^{2}$ result in up to $\$ 4.5$ billion in additional healthcare expenses annually.

Despite huge recent progress in the development of

\footnotetext{
a. Université Paris-Est Créteil (UPEC) - ICMPE UMR CNRS 7182, 61, Avenue du Général de Gaulle, 94010 Créteil cedex.

b. Chimie de la Matière Condensée de Paris, UMR 7574- Equipe "Matériaux et Biologie", Université Pierre et Marie Curie, Bât F, 4 place Jussieu, Paris

Unité Bioemco Equipe IBIOS, UMR 7618 CNRS - Université Paris-Est Créteil Val-deMarne, 61, Avenue Général de Gaulle, 94010 Créteil cedex.

Corresponding author: versace@icmpe.cnrs.fr, Tel : (+33)149781228

Electronic Supplementary Information (ESI) available: A) Number of viable bacteria (per microscope field) seeded on films incubated or not in culture medium for 7 days, and $B$ ) Percentage of dead bacteria on the native and the two different modified PHBHV films (PHBHV-g-PFET and PHBHV-g-PEG 2000 films) (Figure S1) and Live/dead assay: Fluorescence microscopy images of $E$. coli cultured on the PHBHV and on the two modified PHBHV films (PHBHV-g-PFET and PHBHV-g-PEG ${ }_{2000}$ films). Films were incubated for 7 days in culture medium prior bacteria seeding (Day 7) or not (Day 0 ) (Figure S2). See DOI: 10.1039/x0xx00000x
}

polymerization techniques, the design of novel antibacterial surfaces remains a high research priority ${ }^{3-5}$ for scientists. In order to prevent the bacterial colonization of materials surface, intensive efforts have been focused on the modification of the surface architecture, on the improvement of the existing antibacterial surfaces or on the fabrication of new generation surfaces. Two different strategies ${ }^{6-9}$ could be proposed, i.e the active (antimicrobial) and the passive (antifouling, anti-adhesion) strategies. Among the passive systems, perfluorinated molecules ${ }^{10}$ or polymers based on ethylene glycol $^{11,12}$ are the most widely used synthetic materials to reduce nonspecific protein adsorption while recent reports suggest that methylcellulose could provide an interesting bio-based alternative coating ${ }^{13,14}$.

To the best of our knowledge, no reports have hitherto been published on the photografting of methoxy polyethylene glycol sulfhydryl and 2-perfluorooctyl-1-ethanethiol on biocompatible surfaces such as poly(3-hydroxyalkanoate)s (PHAs) in aqueous media to develop anti-biofilm materials with cytocompatible properties. In this study, two thiolderivated monomers have been covalently grafted respectively on a PHA surface and their final anti-adhesion properties have been evaluated against two bacteria strains.

Poly(3-hydroxyalkanoate)s (PHAs) constitute a family of biocompatible aliphatic polyesters ${ }^{15}$ produced by many bacterial microorganisms when subjected to stress conditions. They can be considered as promising biopolymers and have attracted much interest for a variety of biological applications ${ }^{16-22}$, which include controlled drug release, 
fracture repair, bone and cartilage remodelling, antibacterial coatings and tissue engineering in general. To enhance their properties, the direct surface modification of PHA films appears as a real challenge. Many physical or chemical modifications have been developed with the aim of modulating PHAs film surface properties ${ }^{16,17,23-28}$. However, in order to preserve the integrity of the film, mild grafting conditions are required. For this purpose, photoinduced grafting represents a promising way to introduce functional groups on PHA surface. Indeed, this technique is widely known to be a useful "green method" for the functionalization of polymeric materials due to its significant advantages ${ }^{28,29}$ (low cost of operation, innovative technology, mild conditions and substrate-independent method allowing for the covalent deposition of a broad range of polymers). These technical aspects make photopolymerization a particularly useful method for surface modification strategies. Few studies have described so far the potentialities offered by the photografting method for the film surface modification of PHAs. Its feasibility was essentially demonstrated through "grafting-from" polymerization with the use of benzophenone ${ }^{30,31}$, a photosensitive system based on aryl azides ${ }^{32}$, hydrogen peroxide $^{33}$, triarylsulfonium salts ${ }^{24}$ or butan-2-one ${ }^{17,25}$.

Here we have developed a mild and simple method, that involves an aqueous photoinitiated strategy with the use of thiol-derivated monomers, to efficiently functionalize the surface of natural poly(3-hydroxybutyrate-co-3hydroxyvalerate) films. Hydrophobic and hydrophilic surfaces were prepared and carefully characterized. The inhibition of Escherichia coli and Staphylococcus aureus bacteria adhesion was demonstrated. The maintained capacity of these surfaces to allow adhesion and proliferation of normal human dermal fibroblasts is also evidenced. The simplicity, versatility and aqueous conditions of our method open large perspectives for the biofunctionalization of polymer surfaces.

\section{Experimental}

Materials. Poly(3-hydroxybutyrate-co-3-hydroxyvalerate) (PHBHV) with $12 \%$ of 3 -hydroxyvalerate (HV) and a molar mass of 90,000 $\mathrm{g} / \mathrm{mol}$ was purchased from GoodFellow. PHBHV was first purified by dissolution in chloroform for $2 \mathrm{~h}(10 \% \mathrm{w} / \mathrm{v})$ and precipitated in ethanol for removing citric ester used as plasticizer.

Acetone ( $\geq 99.5 \%$ ), Anhydrous $\mathrm{MeOH}(99.8 \%)$, poly(ethylene glycol) methyl ether (average $\mathrm{Mn} \approx 2000 \mathrm{~g} / \mathrm{mol}, \mathrm{MeO}-\mathrm{PEG}_{2000}$ ), potassium thioacetate $(98 \%)$ and methacrylic acid $\mathrm{N}$-hydroxysuccinimide ester (MANHS, 98\%) were purchased from Sigma-Aldrich. p toluenesulfonyl chloride ( $\mathrm{TsCl}, 99+\%)$ and 4-dimethylaminopyridine (DMAP, 99\%) were purchased from Acros Organics. 2perfluorooctyl-1-ethanethiol (Foralkyl ${ }^{\circledR}$ EM8) was supplied from ElfAtochem. Hydrochloric acid $37 \%$ and pyridine synthesis grade were obtained from Carlo Erba. $\mathrm{CH}_{2} \mathrm{Cl}_{2}$ was obtained from Carlo Erba and was distilled over $\mathrm{CaH}_{2}$ before use. THF and toluene were obtained from Carlo Erba and were distilled over sodium/benzophenone before use. The primary dermal fibroblasts have been provided by Promocell (R). All other materials were used without further purification. The structures of the respective monomers and the photoinitiating system are shown in Table 1.

Table 1. Structure of the monomers/polymer and the photoinitiating system used in this study.

Compounds
$\begin{gathered}\text { Poly(3- } \\ \text { hydroxybutyrate- } \\ \text { co-3- } \\ \text { hydroxyvalerate) } \\ \text { (PHBHV) }\end{gathered}$

Mesylation of MeOPEG $_{2000}$. MeOPEG $2000(40 \mathrm{~g}, 20 \mathrm{mmol})$ and triethylamine $(14 \mathrm{~mL}, 0.1 \mathrm{~mol})$ were dissolved in $100 \mathrm{~mL}$ of anhydrous $\mathrm{CH}_{2} \mathrm{Cl}_{2}$ at $0^{\circ} \mathrm{C}$ under argon atmosphere. Methanesulfonyl chloride (7.75 mL, $0.1 \mathrm{~mol}$ ) dissolved in $100 \mathrm{~mL}$ of anhydrous $\mathrm{CH}_{2} \mathrm{Cl}_{2}$ was added dropwise and the solution was stirred overnight (from $0^{\circ} \mathrm{C}$ to RT). $200 \mathrm{~mL}$ of cold water were added and the aqueous phase was extracted three times with $150 \mathrm{~mL}$ of $\mathrm{CH}_{2} \mathrm{Cl}_{2}$. The combined organic phases were successively washed with $3 \times 250 \mathrm{~mL}$ $\mathrm{HCl} 0.1 \mathrm{M}$ solution and $3 \times 250 \mathrm{~mL}$ of saturated $\mathrm{NaCl}$ solution. After drying over $\mathrm{MgSO}_{4}$, the solution was evaporated to approximately $40 \mathrm{~mL}$ and precipitated in $400 \mathrm{~mL}$ of diethyl ether $\left(\mathrm{Et}_{2} \mathrm{O}\right)$. $\mathrm{MeOPEG}_{2000}-\mathrm{OMs}$ was recovered by filtration and dried under vacuum $\left(\mathrm{m}=38.55 \mathrm{~g}\right.$, yield 93\%). ${ }^{1} \mathrm{H}$ NMR $\left(\mathrm{CDCl}_{3}\right) \delta(\mathrm{ppm}) 4.28(\mathrm{~m}$, $2 \mathrm{H}), 3.72-3.34(\mathrm{~m}, 179 \mathrm{H}), 3.26(\mathrm{~s}, 3 \mathrm{H}), 2.98(\mathrm{~s}, 3 \mathrm{H})$.

Synthesis of MeOPEG $_{2000}$-thioacetate. MeOPEG ${ }_{2000}-\mathrm{OMs}$ (38.55 g, $18.6 \mathrm{mmol}$ ) was dissolved in $200 \mathrm{~mL}$ of anhydrous tetrahydrofuran (THF) under argon atmosphere. Potassium thioacetate $(6.35 \mathrm{~g}, 55.6$ mmol) was added and the solution was refluxed for $20 \mathrm{~h}$. A white fluffy precipitate formed. The solution was cooled to room temperature and $200 \mathrm{~mL}$ of $\mathrm{CH}_{2} \mathrm{Cl}_{2}$ were added, followed by $3 \times 100$ $\mathrm{mL}$ washing with $\mathrm{H}_{2} \mathrm{O}$. The brown colored organic phase was treated with activated charcoal, filtered over a pad of silica and rotary evaporated to approximately $50 \mathrm{~mL}$. Finally, the solution was precipitated in $500 \mathrm{~mL}$ of $\mathrm{Et}_{2} \mathrm{O}$, filtrated and the resulting product (MeOPEG ${ }_{2000}$-thioacetate) was dried under vacuum (33.82 g, yield 
88\%). ${ }^{1} \mathrm{H}$ NMR $\left(\mathrm{CDCl}_{3}\right) \delta(\mathrm{ppm}) 3.75-3.37(\mathrm{~m}, 181 \mathrm{H}), 3.29(\mathrm{~s}, 3 \mathrm{H}), 3$ $(\mathrm{t}, J=6.5 \mathrm{~Hz}, 2 \mathrm{H}), 2.25(\mathrm{~s}, 3 \mathrm{H})$.

Synthesis of Methoxy polyethylene glycol sulfhydryl (MeOPEG 2000- $^{-}$ $\mathrm{SH})$. MeOPEG ${ }_{2000}$-thioacetate $(10 \mathrm{~g}, 4.86 \mathrm{mmol}$ ) was dissolved in $100 \mathrm{~mL}$ of $\mathrm{MeOH}$. The solution was degassed and subsequently flushed under argon. $5 \mathrm{~mL}$ of concentrated $\mathrm{HCl}$ was added and the solution was refluxed for $3 \mathrm{~h}$. After cooling to $\mathrm{RT}, 100 \mathrm{~mL}$ of water

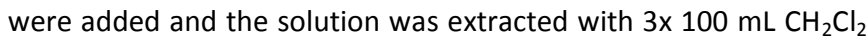
The combined organic phases were subsequently washed with $3 \mathrm{x}$ $100 \mathrm{~mL} \mathrm{H} \mathrm{H}_{2} \mathrm{O}, 1 \mathrm{X} 100 \mathrm{~mL}$ of saturated $\mathrm{NaCl}$ solution and then dried over $\mathrm{MgSO}_{4}$. The resulting solution was rotary evaporated and dried under vacuum to afford colorless thiolated MeOPEG (MeOPEG ${ }_{2000^{-}}$ $\mathrm{SH})\left(9.7 \mathrm{~g}\right.$, yield 97\%). ${ }^{1} \mathrm{H}$ NMR $\left(\mathrm{CDCl}_{3}\right) \delta(\mathrm{ppm}) 3.81-3.43(\mathrm{~m}, 181 \mathrm{H})$, $3.36(\mathrm{~s}, 3 \mathrm{H}), 2.67(\mathrm{dt}, J=8.2,6.5 \mathrm{~Hz}, 2 \mathrm{H}), 1.58(\mathrm{t}, J=8.2 \mathrm{~Hz}, 1 \mathrm{H})$.

Preparation of PHBHV films. To get rid of the plasticizer (citric acid), PHBHV granules $(20 \mathrm{~g})$ were dissolved in $200 \mathrm{~mL}$ of methylene chloride, and stirred at $50{ }^{\circ} \mathrm{C}$ until the solution became completely homogenous. The solution was then precipitated in ethanol solution $(1.5 \mathrm{~L})$. The pure PHBHV was obtained after filtration and dried under vacuum at room temperature during one night. Pure PHBHV powder was placed between two teflon films and baked at $160^{\circ} \mathrm{C}$ for 5 min under pressure of 2 bars. Films with a thickness of $30 \mu \mathrm{m}$ were obtained and cut into pieces of $1.5 \mathrm{~cm} \times 1.5 \mathrm{~cm}$.

Photografting procedures. $300 \mu \mathrm{l}$ of a suitable concentration of the selected monomer solution in distilled water (containing butan-2 one as a photoinitiating system) was added by a micropipette on the surface of the PHBHV film. The thin and uniform liquid layer was sandwiched between PHBHV support and a polypropylene film which is transparent to UV light. Polypropylene film was used to hinder oxygen diffusion inside photopolymerized solution. The both side of the PHBHV film/monomer/polypropylene film assembly were irradiated at room temperature by means of a Lightningcure LC8 (L8251) from Hamamatsu, equipped with a mercury-xenon lamp $(200 \mathrm{~W})$ coupled with a flexible light guide. The end of the guide was placed at a distance of $11 \mathrm{~cm}$. The maximum UV light intensity at the sample position was measured by radiometry (International Light Technologies ILT 393) to be $30 \mathrm{~mW} / \mathrm{cm}^{2}$ in the 250-450 nm. Photografted PHBHV films were then put into distilled water overnight and allowed to dry for one day before characterization.

After the photografting of MANHS on PHBHV surface, MANHS segment forms covalent bonds to thiol groups at cross-linkers. In this cross-linking chemistry, NHS reacts very rapidly with thiol groups and forms covalent bond at thio-ester groups with release of $\mathrm{N}$-hydroxysuccinimide according to the procedure described in literature ${ }^{34-36}$.

Quantitation of surface $\mathbf{C O O H}$ Density. To demonstrate the feasibility of the grafting method, experiments were first done with methacrylic acid (MAA). The density of carboxylate groups on the MAA-grafted PHBHV films was determined using the toluidine blue method. Toluidine blue is a dye which possesses positively charge amine groups and can absorb to the negatively charged carboxylate groups of grafted-MAA, but not to the native PHBHV film surface. Samples were dipped in toluidine blue $(0.1 \mathrm{wt} \%)$ in sodium phosphate buffer $(20 \mathrm{mM}, \mathrm{pH}=8)$ for $5 \mathrm{~min}$, rinsed with water and dried in a nitrogen stream. Toluidine blue is then desorbed from the PHBHV-g-PMAA surface by dipping the film in $25 \mathrm{~mL}$ of 10 wt \% of acetic acid for $10 \mathrm{~min}$. The maximal optical absorption of the dye (at $630 \mathrm{~nm}$ ) released from the PHBHV- $g$-PMAA surface was measured using a spectrophotometer (Varian, Cary 50 Bio). The density of $\mathrm{COO}^{-}$groups on the PHBHV-g-PMAA surface (expressed as $\mathrm{mol} / \mathrm{cm}^{2}$ ) was determined on the hypothesis of a 1:1 ratio between $\mathrm{COO}^{-}$and bound toluidine blue.

Fluorescence microscopy. Inverted microscope IX73 from Olympus equipped with a 75W Xe Lamp housing. The excitation and emission light is filtered with a fluorescence mirror unit (U-FUN from Olympus) associating a band pass filter centered at $365 \mathrm{~nm}$ (BP360370), dichroic mirror (DM410) and long pass filter (BA420IF).

$\mathrm{X}$-ray photoelectron (XPS) measurements. All experiments were performed with a THERMO Kalpha spectrometer with a resolution of $0.5 \mathrm{eV}$. Survey scans were done using monochromatic $\mathrm{Mg} \mathrm{K \alpha} \mathrm{X-}$ ray source with a spot diameter of $400 \mu \mathrm{m}$ and a pass energy of 100 $\mathrm{eV}$. For high resolution core levels, the pass energy was set to $30 \mathrm{eV}$ to increase the resolution. XPS spectra were obtained with an energy step of $0.05 \mathrm{eV}$ with a dwell time of $100 \mathrm{~ms}$. Data acquisitions have mainly been focused on the C1s, O1s, N1s, F1s and S2p3/2 core level lines. The elemental composition as well as element chemical bonding can be deduced from peaks shapes as binding energy of the atomic orbital is strongly influenced by local potential of the emitting atom (initial state effect). The binding energy scale was fixed by assigning a binding energy of $285.1 \mathrm{eV}$ to the $-\mathrm{CH}$ - carbon (1s) peak. In order to avoid charging effects of the non conducting surface, a flood gun has been used for all experiments. The base pressure of the apparatus during data collection was near $1.010^{-9} \mathrm{mbar}$.

Static Contact Angle Measurements. The water contact angle was measured using standard methods. In all the experiments described in this study, static contact angles were measured using a goniometer from Krüss (Easy Drop Krüss). The first step of the measurement was to place a water drop of defined volume on the film surface, which was always exactly horizontal. To apply reproducible uniform volume drops of deionized water, calibrated micropipettes were used; in general, the volume of the water drop was in the range of 15-20 $\mu$ l. Drop shape was automatically recorded with a high speed framing camera, images were then processed by a computer and stored. The uncertainty in the measurements depends on the light-dark contrasts of the drop picture and an error of $3-4^{\circ}$ could be assumed.

Atomic Force Microscopy (AFM). The surface morphology of the films was studied using an AFM Nanosurf C3000 equipment. Height images and profiles were recorded on $10 \mu \mathrm{m}^{2}$ area.

Anti-adhesion property. Initial adhesion assays were performed using two strains of bacteria, namely E. coli ATCC25922 and S. aureus ATCC6538 on the PHBHV modified films. Prior to in vitro anti-adhesion tests, the bacterial strains were grown aerobically overnight in Luria-Bertani broth at $37{ }^{\circ} \mathrm{C}$ under stirring. Overnight cultures of $E$. coli and $S$. aureus grown in Luria-Bertani (LB) broth were diluted to an optical density (OD $600 \mathrm{~nm}$ ) of 0.05 in sterile LB broth. At this point, the reference and modified films $(1.5 \mathrm{~cm} \mathrm{x}$ $1.5 \mathrm{~cm}$ ) were immersed in the culture; the corresponding vials were placed on a slantwise rotating wheel to avoid sedimentation of bacteria, incubated for $1 \mathrm{~h}$ at room temperature and shaken at 150 rpm to allow initial adhesion to occur (INFORS AG-CH 4103, Bottmingen-Basel, Switzerland). Following initial adhesion (1h), the 
samples were rinsed seven times with sterile saline solution $(\mathrm{NaCl}$, $0.9 \% \mathrm{w} / \mathrm{v}$ ) to remove any non-adherent cells.

Colonized native and treated PHBHV films were then transferred to $2 \mathrm{ml}$ sterile saline (solution A) and vortexed vigorously for $30 \mathrm{~s}$. The samples were then transferred to $2 \mathrm{ml}$ sterile saline (solution $B$ ) and sonicated in a Branson 2200 sonicator for $3 \mathrm{~min}$. Samples were transferred once more to $2 \mathrm{ml}$ sterile saline (solution $C$ ) and vortexed vigorously for $30 \mathrm{~s}$. Suspensions $A, B$ and C were pooled, serially diluted and plated on PCA media for viable counting. The cells removed during these three phases represent the loosely attached biofilm population. A $100 \mu \mathrm{L}$ volume of the detached viable bacteria solution was introduced onto the surface of a Plat Count agar plate. The process was repeated through a succession of 24 pre-dried plates. Finally, the total bacterial adhesion was determined by a counting of the CFUs, after overnight statically incubation of the agar plates at $37^{\circ} \mathrm{C}$. Each experiment was done four times. Levels of adhesion were given as numbers of cells per square centimeter.

Statistical analysis. All values corresponding to the anti-adhesion property of $E$. coli and $S$. aureus are expressed as mean \pm standard deviation. Statistical analysis was performed using Student's $t$-test for the calculation of significance level of the data. Differences were considered statistically significant at $P<0.05$. Ten samples per group were evaluated.

Live/dead assay. E. Coli was used for the Live/Dead assay. Bacteria were put in contact with the PHBHV, PHBHV-g-PFET and PHBHV- $g$ $\mathrm{PEG}_{2000}$ films for one hour as previously described. After three rinses in physiological serum for $5 \mathrm{~min}(\mathrm{NaCl} 0.9 \%)$, films were incubated for $10 \mathrm{~min}$ in the Live/Dead assay mixture following the manufacturer's procedure (InVitrogen). Then, the films were rinsed three times in physiological serum for 5 min and mounted between slide and coverslip. Live and dead bacteria were observed using a fluorescence microscope Axio 100 (Zeiss). Live bacteria appeared in green after excitation of Syto 9 at 455-495 nm and detection at 505$555 \mathrm{~nm}$. Dead cells appeared in red after excitation of propidiumiodure at 533-558 $\mathrm{nm}$ and detection at 570-640 nm. Live and dead cells were counted in 10 different microscope fields for each film. Last, the percentage of dead cells was calculated for each sample. Three films for each condition were analyzed and the results were expressed as the mean $+/$ - standard deviation (SD).

Cell culture. Primary dermal fibroblasts were grown in adherent culture flasks in DMEM (Life Technologies) supplemented with 10\% heat-inactivated fetal calf serum and $1 \%$ Penicillin-Streptomycin. Cells were kept at $37^{\circ} \mathrm{C}$ in a humidified $5 \%$ carbon dioxide chamber until confluence was reached. Harvesting was done with a trypsinEDTA solution. Before each use, cells were stained with a $1 \%$ trypan blue solution and counted with a Malassez hematocytometer.

Cell viability. Films were set and maintain at the bottom of wells of a 12 well plates prior to the experiment. Then, primary fibroblasts were seeded at the density $1 \times 10^{5}$ per well. Cell viability on native PHBHV films and those modified with Fluorin (PHBHV-g-PFET) or PEG (PHBHV- $g-$ PEG $_{2000}$ ) was assessed over 7 days. Cell metabolic activity was measured at day 1 and 7 using an Alamar Blue assay ${ }^{\circledR}$ Medium was first removed and rinsed three times with $500 \mu \mathrm{L}$ of colorless DMEM supplemented with $10 \%$ serum. Then, $50 \mu \mathrm{L}$ of Alamar Blue stock solution (Life technologies) was added into the culture medium. Samples were incubated in a humidified $5 \%$ carbon dioxide chamber for 4 hours. Subsequently, media were removed and diluted 1 in 2 in colorless DMEM. The absorbance was recorded at $570 \mathrm{~nm}$ (oxidized resazurin) and $600 \mathrm{~nm}$ (reduced resazurin). Control samples were cells cultured on plastic without films. For each sample, percentage of dye reduction was calculated following the formula provided by the supplier. Last, results were expressed as a percentage of the control (cells cultured on plastic) and normalized with the film surface area. In all cases, results were expressed as mean $\pm S D(n=6)$.

Fluorescence microscopy (evaluation of cytocompatibility). Films were fixed with $4 \%$ paraformaldehyde in PBS for 1 hour, rinsed three times with PBS for 5 min each and incubated with PBS $0.2 \%$ Triton for $20 \mathrm{~min}$. They were then incubated with Alexa Fluor 488 Phalloidin (Molecular Probe ) diluted $1 / 200(\mathrm{v} / \mathrm{v}$ ) in PBS in a dark chamber for $45 \mathrm{~min}$. After three $5 \mathrm{~min}$ rinses in PBS, the samples were incubated with DAPI (Molecular Probe ") diluted 1/50,000 in PBS in a dark chamber for $10 \mathrm{~min}$. Finally, the matrices were washed three times with PBS and mounted between slides and coverslips with AF3 for fluorescence microscopy (ZEISS Axioplan microscope). Fibroblasts were observed at magnification X 10 and X40.

\section{Results and discussion}

3.1 Photografting procedures. The photografting investigation in this study has been performed in accordance with a "green chemistry" procedure in water in a two-step process with the use of butan-2-one (first step) and thiol components addition (second step). Scheme 1 outlines the photografting of PMAA from PHBHV using 2-butanone in aqueous media. The photolysis (( $r 1)$, Scheme 1) of 2-butanone generates both an ethyl radical (A) and an alkoxy adduct radical (B). The free radicals diffuse to the aqueous monomer solution to abstract a hydrogen atom from the PHBHV surface $((r 2)$, Scheme 1$)$. The $(r 2)$ reaction generates free radicals onto the PHBHV surface which initiate the polymerization of PMANHS, thus producing surface-grafted MANHS chains ((r3), Scheme 1). In the second step, MANHS segments form covalent bonds with thiol groups. The reaction is illustrated in Scheme 1 ( $r 4)$. In this chemistry, NHS reacts very rapidly with thiol groups and forms covalent thio-ester bonds with the release of $\mathrm{N}$ hydroxysuccinimide ${ }^{34-36}$.

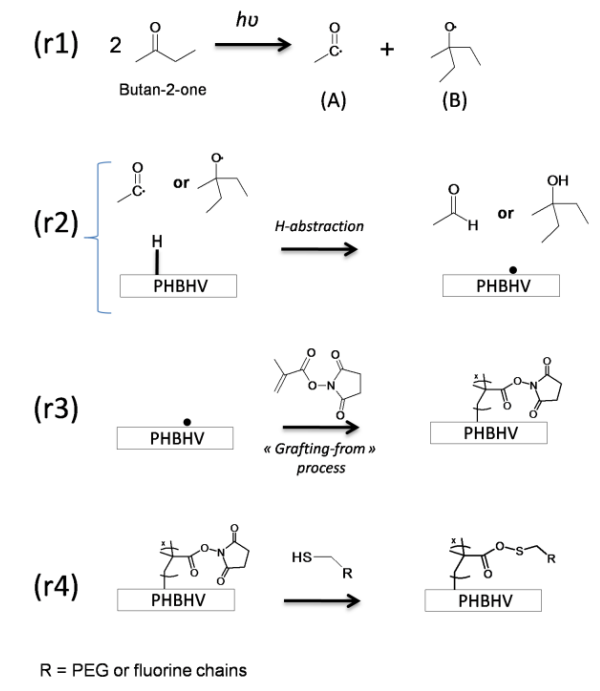


Scheme 1. Global photografting procedure of thiol-derivated monomers on PHBHV films.

To demonstrate the efficiency of the modification of PHBHV surface by covalent photografting described in the first step, methacrylic acid was used as a reference and was grafted upon light activation. The photografting of MAA was revealed on the fluorescence image (Figure 1A). The fluorescence spectrum of the PHBHV-g-PMAA surface following to the toluidine blue method was shown in Figure
1B. The calibration curve of the toluidine blue allowed us to determine the density of $\mathrm{COO}^{-}$function on the PHBHV-g-PMAA surface (Figure $1 \mathrm{C}$ ). According to this method, the density of $\mathrm{COO}^{-}$ grafted on the PHBHV-g-PMAA was evaluated at around $10^{-6}$ mol.cm ${ }^{-2}$, thereby confirming the efficiency of the photoinduced grafting. It is also interesting to point out that the fluorescence of the films only occured when PMAA was grafted.


Figure 1. A) Fluorescence image of the PHBHV-g-PMAA film modified with toluidine blue, B-1) Fluorescence background spectrum of the PHBHV film soaped in the toluidine blue solution and intensively washed with water, B-2) fluorescence spectrum of the corresponding modified PHBHV-g-PMAA film with toluidine blue and C) OD at $630 \mathrm{~nm}$ of the toluidine blue molecules grafted on PHBHV-g-PMAA film after different irradiation times (Irradiation: lamp Hg-Xe, light intensity $=30 \mathrm{~mW} . \mathrm{cm}^{-2}$ ).

The ATR-FTIR of the native PHBHV film shows typical absorption bands such as $-\mathrm{C}-\mathrm{H}$ aliphatic and asymmetric stretching band likewise a $-\mathrm{C}=\mathrm{O}$ stretching band from an ester group at, respectively, $2870-3010 \mathrm{~cm}^{-1}$ and at $1720 \mathrm{~cm}^{-1}$ (Figure 2). When the methacrylic acid $\mathrm{N}$-hydroxysuccinimide ester (PMANHS) monomer is grafted on PHBHV surface films, the characterized methacrylate band at $1636 \mathrm{~cm}^{-1}$ disappears. This demonstrates the consumption of the methacrylate double bonds by the "grafting-from" process and, therefore, the efficiency of the photografting method. In the PHBHV- $g-$ PEG $_{2000}$ film, a broad band between $2900-3400 \mathrm{~cm}^{-1}$ and attributed to the appearance of water on the PEG surface, which is hydrophilic and hygroscopic, indicates that the grafting of $\mathrm{PEG}_{2000}$ onto PHBHV occurred. When grafting 2-perfluorooctyl-1ethanethiol (PFET) onto the modified-PHBHV surface, the broad band between 2900 and $3400 \mathrm{~cm}^{-1}$ no longer appears and a new C-F stretching band appears at $1200 \mathrm{~cm}^{-1}$.

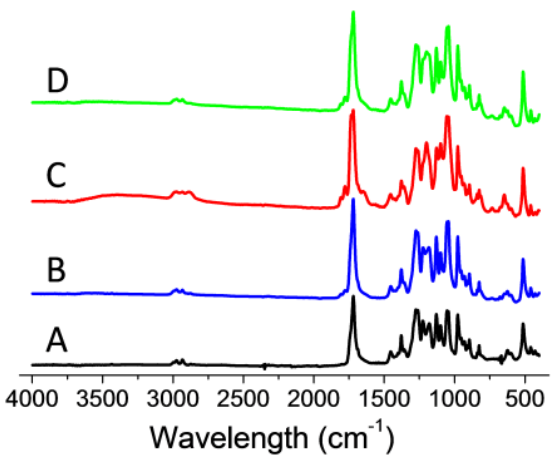

Figure 2. ATR-FTIR spectra of A) native PHBHV; B) PHBHV-gPMANHS modified film; C) PHBHV- $g-\mathrm{PEG}_{2000}$ modified film and D) PHBHV-g-PFET modified film. 
Table 2 summarizes the water contact angle for the native and the modified PHBHV surfaces. For the native PHBHV film, the water contact angle was evaluated at $85^{\circ}$. When the methacrylic acid $\mathrm{N}$ hydroxysuccinimide ester is grafted, the contact angle drops down to $63^{\circ}$, whereas it falls down at approximately $23^{\circ}$ when the grafting reaction occurred with PEG2000, indicating that the film is more hydrophilic due to the $-\mathrm{OH}$ function at the surface. Concerning the 2-perfluorooctyl-1-ethanethiol (PFET) grafted PHBHV films, the water contact angle increases to $96^{\circ}$ : it could be explained by the fact that PFET is a very hydrophobic component, thus demonstrating that the grafting occurred.

Table 2. Evolution of the water contact angles of the native and the modified PHBHV films.

\begin{tabular}{lc}
\hline Modified PHBHV films & Water contact angle $^{\text {a }}$ \\
\hline PHBHV & $85^{\circ} \pm 2^{\circ}$ \\
PHBHV-g-PMANHS & $63.5^{\circ} \pm 2.6^{\circ}$ \\
PHBHV- $g$-PFET & $96^{\circ} \pm 2.7^{\circ}$ \\
PHBHV- $g$-PEG & $23.8^{\circ} \pm 3.2^{\circ}$ \\
\hline
\end{tabular}

${ }^{a}$ Average on 6 samples

The film surface morphology was studied by AFM (Figure 3). The unmodified PHBHV films exhibit a disordered particulate surface resulting from the aggregation of polymer grains (Figure $3 \mathrm{~A}$ ). PEGylated surfaces of the films showed smoother surfaces than the native ones (Figure 3B). After fluorination, the surface of the corresponding films was also smoother than the bare films, and submicronic pits or pores could be observed (Figure 3C). The surface roughness or surface irregularities are not so significant (less than $200 \mathrm{~nm}$ between the highest and the lowest point for the different modified surface) to exert influence on micrometric bacteria behavior.


Figure 3. AFM height and profile images of A) native PHBHV film, B) PHBHV- $g$-PEG 2000 film and c) PHBHV-g-PFET film.

In order to investigate the chemical changes of the modified PHBHV surfaces, XPS measurements have been performed. Data acquisitions have mainly been focused on the S2p3/2, N1s, $S_{2 p 3 / 2}$, and F1s core level lines. XPS survey-scan spectra for the unmodified PHBHV film and the PHBHV-modified films with MANHS, PEG-SH and Fluor-SH are displayed in Figure 4.

For the native PHBHV film, the $\mathrm{C} 1 \mathrm{~s}$ spectrum revealed the appearance of three main components, aliphatic carbon (C-H/C-C) at $285.1 \mathrm{eV}, \mathrm{C}-\mathrm{O}$ bond at $286.7 \mathrm{eV}$ and carbon from carbonyl group $\left(\mathrm{O}-\mathrm{C}=\mathrm{O}\right.$ ) at $289.2 \mathrm{eV}$ in good agreement with the literature ${ }^{25}$ (Figure $4 \mathrm{~A})$. However, neither fluorine nor nitrogen peaks have been observed. In the PHBHV-g-PMANHS film, a new nitrogen (N1s) peak from the $\mathrm{N}$-hydroxysuccinimide group is observed at $402 \mathrm{eV}$ (Figure $4 \mathrm{~B})$. After the addition of the methoxy polyethylene glycol sulfhydryl on the PHBHV-g-PMANHS film, the nitrogen peak disappears and a new sulfur $\left(\mathrm{S}_{2 \mathrm{p} 3 / 2}\right)$ peak appears at $164 \mathrm{eV}$ (Figure $4 C$ ). In the fluorine grafted PHBHV film, an intense fluorine (F1s) peak appears at $689 \mathrm{eV}$. It is interesting to notice that the disappearance of the N1s peak demonstrates the release of $\mathrm{N}$ hydroxysuccinimide from the PHBHV surface. 


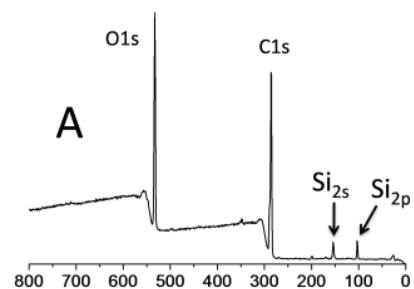

Binding energy $(\mathrm{eV})$

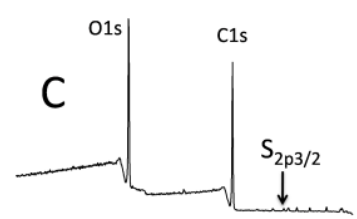

$800 \quad 700 \quad 600 \quad 500 \quad 400 \quad 300 \quad 200 \quad 100$ Binding energy $(\mathrm{eV})$


$800 \quad 700 \quad 600 \quad 500 \quad 400 \quad 300 \quad 200 \quad 100$ Binding energy $(\mathrm{eV})$
Figure 4. XPS survey-scan spectra of (A) PHBHV film, (B) PHBHV-gPMANHS film, (C) PHBHV-g-PEG2000 film and D) PHBHV-g-PFET film Irradiation time $=260 \mathrm{~s}$. Light intensity $=40 \mathrm{~mW} . \mathrm{cm}^{-2} . \mathrm{Hg}-$ Xe lamp.

3.2. Anti-adhesion properties. The anti-adhesion property of polymers grafted with PEG or fluorine group are of great interest for the prevention of bacterial adhesion and proliferation on material surfaces. Immobilizing PEG is the one of the most commonly used approaches to prevent bio-adhesion and PEGbased coatings with anti-adhesion properties have been widely described in literature ${ }^{37}$. In contrast, few investigations concern the antimicrobial activities of fluorinated surfaces ${ }^{38,39}$. To the best of our knowledge, the anti-bacterial properties of PEGylated or fluorinated PHBHV films have never been reported so far.

The efficiency of the PHBHV-g-PFET films vs PHBHV- $g$-PEG ${ }_{2000}$ films to inhibit bacterial adhesion was investigated against GramNegative bacteria (E. coli) and Gram-Positive bacteria (S. aureus) and compared with the native PHBHV films (Figure 5). A quantitative has been used as reported in many antibacterial investigations ${ }^{40,41}$.

PHBHV film did not exhibit anti-adhesion property against $E$. coli and $S$. aureus adhesion. In contrast, the presence of fluorine groups onto the surface led to a reduction by $97 \%$ and $90 \%$ of the adhesion of $E$. coli and $S$. aureus, respectively. Such results are in accordance with literature data ${ }^{38,39}$. Indeed Guittard's group have developed different perfluoroalkyl polymers and demonstrated their strong antimicrobial capacity against $P$. aeruginosa, $S$. aureus bacteria, $C$. albicans and $A$. niger fungus as no bacteria was detected after $1 \mathrm{~h}$ of contact. They explained that the antimicrobial activity of the fluorine-containing polymers was associated with their surface activity and their high hydrophobic character.



Figure 5. Comparison of anti-adhesion property of native PHBHV, PHBHV-g-PFET modified film and PHBHV-g-PEG 2000 modified films against $E$. coli and $S$. aureus. Adhesion time $=1 \mathrm{~h}$. Data are shown as mean \pm standard deviation $(n=6)$. Results indicate significant difference obtained by t-test $(*$ for $\mathrm{P}<0.05)$.

Interestingly, the inhibition was higher on PHBHV- $g-\mathrm{PEG}_{2000}$ films, i.e the adhesion of $E$. coli and $S$. aureus was drastically reduced by $99 \%$ and $98 \%$ respectively. When $\mathrm{PEG}_{550}$ is grafted on PHBHV film surface (not shown here), the two strains adhere in the same manner than pristine PHBHV film, thus revealing no anti-adhesion activity. Our results are in agreement with literature investigations $^{11,37,42}$ as it has been demonstrated that PEG chains exhibit large steric repulsion forces, which can impede the approach of bacteria towards the surface. In general, high molecular weight PEGs $(2000 \mathrm{~g} / \mathrm{mol})$ exhibited greater resistance to bacterial attachment than the lower molecular weight ones $(550 \mathrm{~g} / \mathrm{mol})$. In parallel, it was checked that the modified PHBHV films preserved their bacteria repellent capacity after 7 day of incubation in cell culture medium (ESI), thereby evidencing that the surface functionalization is stable in physiological conditions. After 7 days of incubation and whatever the modified PHBHV films used, more than $95 \%$ of the initial seeded bacteria were dead (Figure S1, ESI), i.e. most of the bacteria appeared in red color on the surface of the modified PHBHV films according to the live/dead assay (Figure S2, ESI). In contrast, around $50 \%$ of the bacteria on the native PHBHV surface were alive (green color) after 7 days (Figure S2, ESI).

These results clearly indicated that the grafting of fluorine groups or PEG chains on the surface of PHBHV films is a powerful method for substantially enhancing the anti-adhesion property (this is particularly true with $E$. coli) and can prevent the biofilm formation on material surfaces. In conclusion, this antibacterial effect is due to the chemical surface modification of the PHBHV film rather than the surface topography.

3.3 Cytotoxicity of Polyester Films towards Primary Fibroblasts. Modified-PHBHV films could be used as a film coating and be eligible for applications where biocompatibility and anti-adhesion properties are needed such as dental devices. Therefore, it is 
important to check whether the modified PHBHV films are not detrimental to mammalian cells.

Cytotoxicity of these films towards primary human dermal fibroblasts was evaluated by Alamar Blue assay after one and seven days (Figure 6). Results were expressed as a percentage of the viability assessed in control samples (cultured on plastic) at day 1 Fibroblasts showed a high viability after 24 hours, regardless of the type of films (more than $100 \%$ of control). The cell viability measured on PHBHV-g-PEG 2000 and PHBHV-g-PFET was not significantly different than that measured in control samples (on plastic dishes). In contrast, cells cultured on PHBHV films exhibited cell viability slightly higher than that assessed on the other films. At day 7 , the metabolic activity increased by about $30 \%$ in all conditions except for PHBHV films. At this time point, no difference of cell viability was observed on the films and on plastic. This increase of cell viability corresponded to the proliferation of cells to reach confluency. These results showed that PHBHV films did not alter cell adhesion and did not impact the cell proliferation regardless of the functionalization considered.

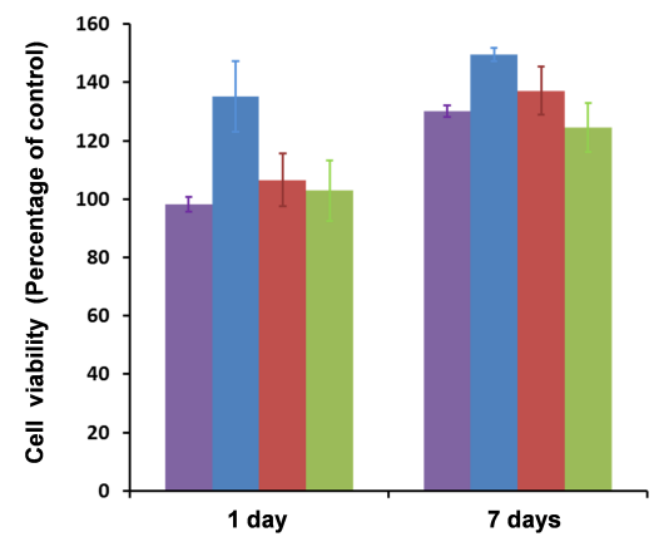

= Control

= Native PHBHV

- PHBHV-g-PFET

$=$ PHBHV-g-PEG2000
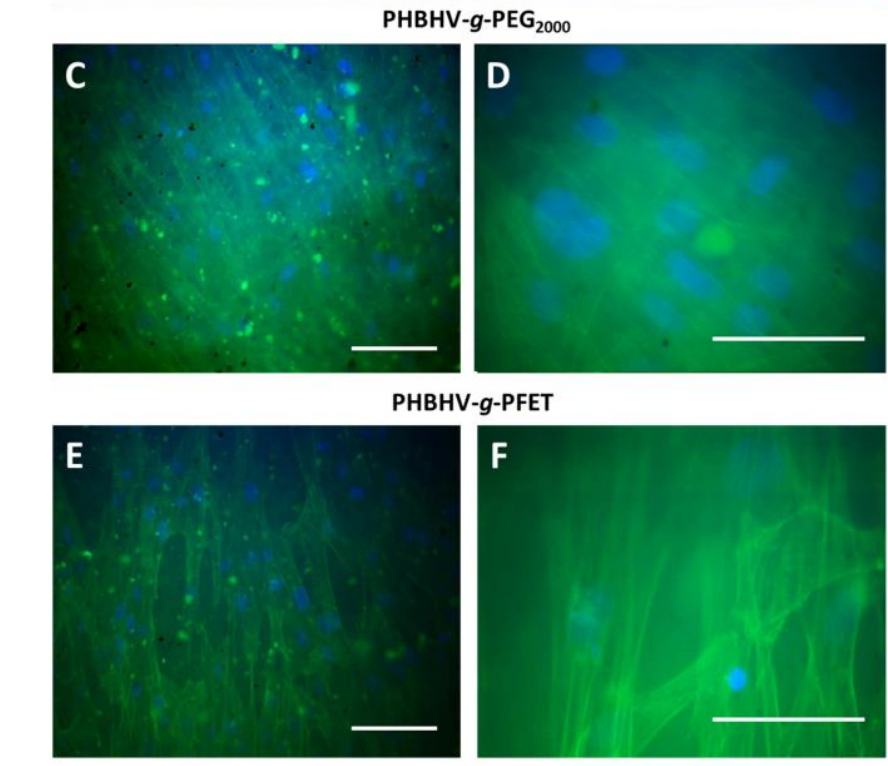

BHV
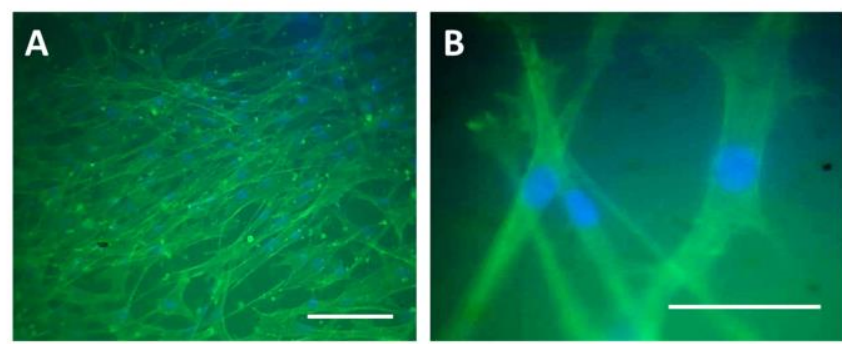

PHBHV-g-PEG 2000

PBHV- $g$-PFET

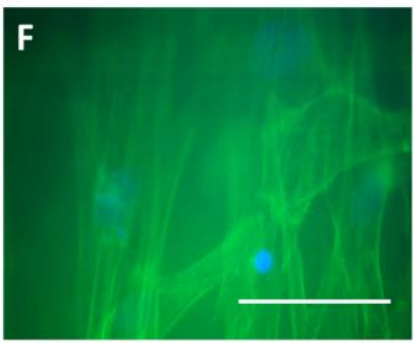

Figure 7. Cell morphology of human primary dermal fibroblasts cultivated on native and functionalized films. Fibroblasts attached and spread when they were in contact with polyester films $(A, B)$, PEG functionalized films (C, D) and fluorine functionalized films ( $E$,

Figure 6. Cell viability of primary human dermal fibroblasts on functionalized PHBHV films.

3.4 Cell morphology of human fibroblasts on functionalized films.

Cell morphology was observed 7 days after seeding by fluoresence microscopy. Regardless of the material studied, fibroblasts succeeded to adhere to their support (Figure 7). When the cells were cultivated on PHBHV films, they spread and exhibited a spindle shape morphology (Figures $7 \mathrm{~A}$ and $7 \mathrm{~B}$ ). Stress fibers consisting of actin filaments were visible. This morphology was typically that of fibroblasts cultivated in 2 dimensions on a plastic dish. Moreover, actin filaments were thin and some filopodia were observed. These features might be due to weaker cell/film interactions or to the film softness. Fibroblasts cultivated on PHBHV-g-PEG ${ }_{2000}$ and PHBHV-g-PFET also exhibited a spindle shape with the presence of large stress fibers (Figures 7C, 7D, 7E and 7F). Their morphology was slightly different of that observed with PHBHV. Cells looked larger than those cultivated on unfunctionalized materials (PHBHV films). In addition, the number of actin filaments was higher. As cells adapted their morphology according to their support, functionalization either promoted cell
F). Nuclei were stained in blue with DAPI and actin cytoskeleton in green with Alexa Fluor 488 Phalloidin. Bar: $50 \mu \mathrm{m}$.

\section{Conclusions}

PHBHV-derived polymer films with bacteria-repellent properties were successfully engineered using a photoactivated process in an aqueous media. In vitro assessment of their biological response suggests that neither the chemical process nor the surface modification significantly impact on the behavior of human skin cells. Such films or coatings could be eligible for applications where biocompatibility and anti-biofilm properties are needed such as orthopedic devices. Its aqueous conditions are compatible with many biological molecules, such as peptides or sugars, offering a promising route for the easy biofunctionalization of a wide range of biomaterials. 


\section{Acknowledgements}

The authors would like to thank the CNRS institute for financial supports.

\section{References}

1. G. Ducel, J. Fabry and L. Nicolle, Prevention of hospitalacquired infections: a practical guide, Geneva, Switzerland: World Health Organization, 2nd edn., 2002.

2. J. L. Pace, M. E. Rupp and R. G. Finch, Biofilms, Infections, and Antimicrobial Therapy, CRC Press Taylor and Francis Group, 2006.

3. C. R. Arciola, D. Campoccia, P. Speziale, L. Montanaro and J. W. Costerton, Biomaterials, 2012, 33, 5967-5982.

4. K. Bazaka, M. Jacob, R. Crawford and E. Ivanova, Appl Microbiol Biotechnol, 2012, 95, 299-311.

5. J. C. Tiller, C.-J. Liao, K. Lewis and A. M. Klibanov, Proc. Natl. Acad. Sci., 2001, 98, 5981-5985.

6. J. S. Kim, E. Kuk, K. N. Yu, J.-H. Kim, S. J. Park, H. J. Lee, S. H. Kim, Y. K. Park, Y. H. Park, C.-Y. Hwang, Y.-K. Kim, Y.-S. Lee, D. H. Jeong and M.-H. Cho, Nanomedicine: Nanotechnology, Biology and Medicine, 2007, 3, 95-101.

7. C.-N. Lok, C.-M. Ho, R. Chen, Q.-Y. He, W.-Y. Yu, H. Sun, P.-H. Tam, J.-F. Chiu and C.-M. Che, J Biol Inorg Chem, 2007, 12, 527 534.

8. S. Ye, P. Majumdar, B. Chisholm, S. Stafslien and Z. Chen, Langmuir, 2010, 26, 16455-16462.

9. Q. Yu, Z. Wu and H. Chen, Acta Biomaterialia, 2015, 16, 1-13. 10. J. Genzer and K. Efimenko, Biofouling, 2006, 22, 339-360.

11. K. D. Park, Y. S. Kim, D. K. Han, Y. H. Kim, E. H. B. Lee, H. Suh and K. S. Choi, Biomaterials, 1998, 19, 851-859.

12. E. Ostuni, R. G. Chapman, M. N. Liang, G. Meluleni, G. Pier, D. E. Ingber and G. M. Whitesides, Langmuir, 2001, 17, 6336-6343.

13. J. Lafarge, N. Kébir, D. Schapman, V. Gadenne and F. Burel, Cellulose, 2013, 20, 2779-2790.

14. W. Mussard, N. Kebir, I. Kriegel, M. Estève and V. Semetey, Angew. Chem. Int. Ed., 2011, 50, 10871-10874.

15. K. Sudesh, H. Abe and Y. Doi, Progr. Polym. Sci., 2000, 25 1503-1555.

16. D.-L. Versace, J. Ramier, J. Babinot, P. Lemechko, O. Soppera,

J. Lalevee, P. Albanese, E. Renard and V. Langlois, J. Mater. Chem. B, 2013, 1, 4834-4844.

17. D.-L. Versace, J. Ramier, D. Grande, S. A. Andaloussi, P. Dubot, N. Hobeika, J.-P. Malval, J. Lalevee, E. Renard and V. Langlois, Adv. Healthcare Mater., 2013, 2, 1008-1018.

18. G.-Q. Chen and Q. Wu, Biomaterials, 2005, 26, 6565-6578.

19. Y.-W. Wang, F. Yang, Q. Wu, Y.-c. Cheng, P. H. F. Yu, J. Chen and G.-Q. Chen, Biomaterials, 2005, 26, 755-761.

20. J. Babinot, J.-M. Guigner, E. Renard and V. Langlois, Chem. Comm., 2012, 48, 5364-5366.

21. S. K. Misra, S. P. Valappil, I. Roy and A. R. Boccaccini, Biomacromolecules, 2006, 7, 2249-2258.

22. M. Zinn, B. Witholt and T. Egli, Adv. Drug Delivery Rev., 2001, 53, 5-21.
23. T. H. Ying, D. Ishii, A. Mahara, S. Murakami, T. Yamaoka, K. Sudesh, R. Samian, M. Fujita, M. Maeda and T. Iwata, Biomaterials, 2008, 29, 1307-1317.

24. D.-L. Versace, P. Dubot, P. Cenedese, J. Lalevee, O. Soppera, J.-P. Malval, E. Renard and V. Langlois, Green Chem., 2012, 14, 788-798

25. G. M. Manecka, J. Labrash, O. Rouxel, P. Dubot, J. Lalevée, S. A. Andaloussi, E. Renard, V. Langlois and D. L. Versace, ACS Sustainable Chem. Eng., 2014, 2, 996-1006.

26. Y.-Y. Wang, L.-X. Lü, J.-C. Shi, H.-F. Wang, Z.-D. Xiao and N.-P. Huang, Biomacromolecules, 2011, 12, 551-559.

27. L. Grøndahl, A. Chandler-Temple and M. Trau, Biomacromolecules, 2005, 6, 2197-2203.

28. J. Babinot, E. Renard, V. Langlois and D. L. Versace, in Dyes and Chromophore in Polymer Science, eds. J.-P. Fouassier and J. Lalevée, John Wiley \& Sons, 2015, ch. 10.

29. J. P. Fouassier and J. Lalevée, Photoinitiators for Polymer Synthesis: Scope, Reactivity, and Efficiency, John Wiley \& Sons, 2012.

30. H.-K. Lao, E. Renard, A. E. Fagui, V. Langlois, K. Vallée-Rehel and I. Linossier, J. Appl. Polym. Sci., 2011, 120, 184-194.

31. H. Ma, R. H. Davis and C. N. Bowman, Macromolecules, 2000, 33, 331-335.

32. B. Rupp, C. Ebner, E. Rossegger, C. Slugovc, F. Stelzer and F. Wiesbrock, Green Chem., 2010, 12, 1796-1802.

33. H.-K. Lao, E. Renard, V. Langlois, K. Vallée-Rehel and I. Linossier, J. Appl. Polym. Sci., 2010, 116, 288-297.

34. A. Hill, T. D. Estridge, M. Maroney, E. Monnet, B. Egbert, G. Cruise and G. T. Coker, J. Biomed. Mater. Res. , 2001, 58, 308312.

35. D. G. Wallace, G. M. Cruise, W. M. Rhee, J. A. Schroeder, J. J. Prior, J. Ju, M. Maroney, J. Duronio, M. H. Ngo, T. Estridge and G. C. Coker, J. Biomed. Mater. Res. , 2001, 58, 545-555.

36. H. Chung and R. H. Grubbs, Macromolecules, 2012, 45, 96669673.

37. I. Banerjee, R. C. Pangule and R. S. Kane, Adv. Mater., 2011, 23, 690-718.

38. P. Thebault, E. T. d. Givenchy, S. Géribaldi, R. Levy, Y. Vandenberghe and F. Guittard, J. Fluorine Chem., 2010, 131, 592-596.

39. F. Guittard and S. Geribaldi, J. Fluorine Chem., 2001, 107, 363-374.

40. S. E. Habnouni, V. Darcos, X. Garric, J.-P. Lavigne, B. Nottelet and J. Coudane, Adv. Funct. Mater., 2011, 21, 3321-3330.

41. D. J. Balazs, K. Triandafillu, P. Wood, Y. Chevolot, C. v. Delden, H. Harms, C. Hollensteind and H. J. Mathieu, Biomaterials, 2004, 25, 2139-2151.

42. A. Roosjen, H. C. V. D. Mei, H. J. Busscher and W. Norde, Langmuir, 2004, 20, 10949-10955. 
10 | J. Name., 2012, 00, 1-3 


\section{TABLE of CONTENTS}

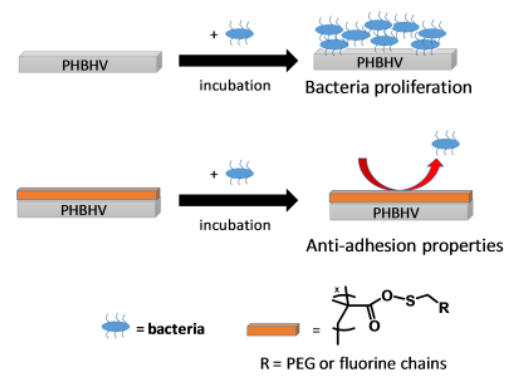

Design of cytocompatible bacteria-repellent bio-based Polyester surfaces in aqueous media 